\title{
Sertraline alters level of adenosine deaminase activity, oxidative stress markers and cardiac biomarkers (homocysteine cardiac troponin I) in rats
}

\author{
Kaveh Azimzadeh ${ }^{1 *}$, Hossein Jafarpour ${ }^{2}$, Sadra Adldoost ${ }^{2}$ \\ ${ }^{1}$ Young Researcher and Elite Club, Urmia Branch, Islamic Azad University, Urmia, Iran \\ ${ }^{2}$ Student of Veterinary Medicine, Veterinary faculty, Urmia Branch, Islamic Azad University, Urmia, Iran

\begin{tabular}{|c|c|}
\hline ART I C LE I NFO & ABSTRACT \\
\hline $\begin{array}{l}\text { *Corresponding author: } \\
\text { kaclinpath@gmail.com }\end{array}$ & \multirow{7}{*}{$\begin{array}{l}\text { The aim of this study is whether oxidative stress markers, homocysteine (Hcy), cardiac troponin I (cTnI) } \\
\text { and the activity of adenosine deaminase (ADA) alter following administration of different doses of } \\
\text { sertraline. Sixty male Wistar rats were assigned into four groups. Sertraline at doses of } 20,40 \text { and } 80 \mathrm{mg} / \\
\mathrm{kg} / \text { day) were administered to three groups through gastric gavage for } 90 \text { days. The fourth group was } \\
\text { received only distilled water. After } 90 \text { days of sertaline administration, the levels of oxidative stress } \\
\text { biomarkers in plasma were measured. The results revealed remarkable elevation in malondialdehyde } \\
\text { (MDA) and considerable reduction in Hcy, cTnI, antioxidant enzymes levels as superoxide dismutase } \\
\text { (SOD), glutathione peroxidase (GSH-Px), catalase and paraoxonase (PON)and ADA activity in the rats that } \\
\text { were receive sertraline at dose of } 80 \mathrm{mg} / \mathrm{Kg} / \text { day. The results denoted that sertraline administration at } \\
\text { the dose of } 80 \mathrm{mg} / \mathrm{kg} / \text { day reduce cardiovascular biomarkers. Meanwhile, decrease of ADA activity may } \\
\text { suggest reduction of immune function due to sertraline administration. }\end{array}$} \\
\hline Article history: & \\
\hline Received: Apr 11, 2017 & \\
\hline Accepted: Aug 20, 2017 & \\
\hline Keywords: & \\
\hline Sertraline, & \\
\hline $\begin{array}{l}\text { Biochemical } \\
\text { parameters, } \\
\text { rat }\end{array}$ & \\
\hline
\end{tabular}

Citation: Pharm Biomed Res 2017;3(3): 17-22.

\begin{abstract}
Introduction
Depression is known as a devastating disease that impairs the numerous physical and psychosocial dysfunction and can occur at any age with symptoms and sometimes the power to overcome depression induced psychosocial stress decrease. Antidepressants drugs are known the third group of drugs that are utilized in human medicine. Among these drugs, serotonin re-uptake inhibitors are considered as important ones. Sertraline is pointed out as antidepressant drugs that is derived from naphthylamine group which is widely applied as an effective drug in the control and treatment of depression $(1,2)$. In addition, several studies have been reported that sertraline stimulates neurogenesis and possesses antioxidant effects $(3,4)$. Oxidative stress has a crucial role in the pathophysiology of depression. As increased free radical production and/or reduction of antioxidant agents (such as antioxidant enzymes) which causes oxidative stress is associated with depression $(1,2)$. Reactive oxygen species (ROS), are incessantly produced following metabolic reactions. Oxidative stress occurred during the excessive production of ROS and antioxidant deficiencies and can provoke some reactions that ultimate to cell injury or cell death. On the other word, oxidative stress, affects polyunsaturated fatty acids and cause lipid peroxidation which can be utilized as markers of stress oxidative $(5,6)$. Malondialdehyde
\end{abstract}

(MDA) as a product of lipid peroxidation, is known reliable indicator to assess lipid peroxidation. It should be noted that the neurological disease and major depressive disorder (MDD) is related to oxidative stress (7).

Adenosine deaminase (ADA), as one of the essential enzymes, is involved in the metabolism of purines maturation and function of $\mathrm{T}$ cells and plays substantial effect in the nervous, immune and vascular systems (8). ADA is called as an important enzyme in T-lymphocyte differentiation and ADA activity is more in T-lymphocytes than B-lymphocytes. The high activity of ADA has been observed in inflammatory diseases associated with cell-mediated immunity and is pointed out as a marker of cellular immunity and Tlymphocytes activity and close relationship between ADA and neutrophils-mediated free radicals (nitric oxide and ROS) production has been referred in some studies. In addition, it was observed a correlation between purine metabolism and anxiety (9).

Homocysteine (Hcy) is categorized as thiolcomprising amino acid which consequently generated during methionine metabolism. In this metabolism, vitamin B12 and folic acid participate in the methylation of homocysteine into methionine and those ones deficiency play essential factor in Hcy elevation. Hyperhomocysteinemia causes oxidative stress and is known as one of the major risk factors of 
atherosclerosis, vascular endothelial cell damage and nerve cells and also involves in several mental disorders, including depression, schizophrenia and Alzheimer disease (10).

Myofibrillar proteins such as troponin I, C and T modulate interaction between actin and myosin through calcium in the myocardium (11). Among them, cardiac troponin I (cTnI) is considered as high accurate specific biomarker of myocardium damage (12). Following, enhancement of cardiomyocytes permeability and damage, cTnI releases into blood as a marker for the diagnosis of heart muscle damage and positive correlation has been identified between blood concentrations of cTnI and myocardial damage $(13,14)$.

With regards to use of SSRIs in patients, it seems that sertraline, as one of SSRIs, affects on the some biochemical parameters, especially cardiac biomarkers, may involve in the management of drug usage.

\section{Materials and Methods \\ Protocol of study}

In this study, sixty Wistar rats (male) $(21 \pm 175 \mathrm{~g})$ were purchased from Urmia University. Then the rats were arbitrarily assigned to four groups and were kept in special cages under standard and hygienic situation. Also the environment temperature and its humidity were assigned $21-25{ }^{\circ} \mathrm{C}$ and $41 \%$, respectively and water along with pellet were placed ad libitum. This study was approved by Veterinary Faculty of Urmia Islamic Azad University, in terms of ethical principles $(02 / 13 / 34831)$.

\section{Drug administration}

After 10 days of adaptation period, sertraline (Tehran Darou Co. Tehran, Iran) was administered by gastric gavage for 90 days for three groups, respectively, at doses of 20, 40 and $80 \mathrm{mg} / \mathrm{kg} /$ day) and the fourth group only was received distilled water.

\section{Blood sampling and determination of oxidative stress profiles}

After 3 months, all the rats were anaesthetized (pentobarbital sodium, $50 \mathrm{mg} / \mathrm{kg}$, i.p) and blood sampling were carried out through heart and were transferred to heparinized tubes and part of it was removed for determination of antioxidant enzymes activity (CAT, SOD, GSH-Px, PON) and remained blood samples were centrifuged for 10 minutes (5000 rpm). Plasma MDA and PON were detected through Satoh and Furlong methods respectively (Spectrophotometer, Cecil, Italy). The SOD, GSH-Px, were determined in lysed red blood cells (by autoanalyzer, Alcyon-300, USA), (Ransod® and Ransel kits, Randox laboratories Ltd. G.B) and CAT activity was detected based on Aebi method (30).

\section{Measurment of cardiac biomarkers and ADA}

The cTnI was assessed by Elisa technique (Cobas Co.) and Hcy was measured by Colorimetric method (Spekoll 1500) (Parsazmoon company, Tehran, Iran). The ADA activity was determined using electrochemiluminescence technique (ECL) (Elecsys, Roche, 2010).

\section{Statistical analysis}

Statistical analysis was accomplished in all analyses. The data were denoted as Mean \pm SD. The statistical analysis of data was performed by one-way ANOVA test. The statistical package of SAS v9.1 (SAS Institute Inc., Cary, NC, USA) was allocated and significant level was set at $\mathrm{P}<0.01$.

\section{Results}

Table 1 demonstrates alterations of cTnI, ADA and Hcy in different treatment groups rather than control group. The low level of cTnI (9.12 \pm 2.39$)$ (17\%) was observed during sertraline administration in $80 \mathrm{mg} / \mathrm{kg}$ dose and reached almost one-third of the concentration in the control group and no remarkable alterations were resulted in the other groups in comparison with control group. A significantly reduction in ADA level was observed in $80 \mathrm{mg} / \mathrm{kg}$ dose group (15.12 \pm 0.67 ) (p $\leq 0.01)(21 \%)$ rather than other treatment groups and control ones. It is worth mentioning that in 40 $\mathrm{mg} / \mathrm{kg}$ dose, only significant elevation of Hcy (11.86 \pm 0.76 ) (13\%) was observed.

The results of Table 2 show significant elevation ( $p$ $\leq 0.01)$ of MDA (3.02 \pm 0.42$),(4 \%)$ almost three times of control group. in $80 \mathrm{mg} / \mathrm{kg}$ treated group as compared to other groups. In terms of antioxidant enzymes, noticeable reduction was revealed in 80 $\mathrm{mg} / \mathrm{kg}$ dose, $1028.19 \pm 72.59$ (31\%) in SOD, $35.18 \pm$ $3.61(14 \%)$ in CAT, $41.48 \pm 2.29$ (24\%) in GSH-Px and $31.64 \pm 5.16(21 \%)$ in PON.

\section{Discussion}

Neurons and glial cells more prone than other cells to free radicals, because levels of unsaturated fatty acids are high and somewhat the antioxidants levels are low. This makes them susceptible to free radical attack. Thus, increased levels of free radicals (FR) and/or decrease of their removal may result oxidative stress in CNS cells (6). Oxidative stress characterized with high MDA level, as lipid peroxidation index, and decreased antioxidant enzymes such as SOD, CAT and GSh-Px. MDA possesses several harmful effects on cell membranes (such as an increase of their permeability) and can easily be combined with some of the molecules in the cell membrane (5). In addition, MDA has harmful effects on receptors of serotonin and may cause to deterioration of 
Table 1 Comparison of cardiac biomarkers and ADA following sertraline administration with different doses between treatment and control groups

\begin{tabular}{|c|c|c|c|c|c|}
\hline group & control & $40 \mathrm{mg} / \mathrm{kg} /$ day & $80 \mathrm{mg} / \mathrm{kg} /$ day & $20 \mathrm{mg} / \mathrm{kg} /$ day & pvalue \\
\hline Hcy (U/L) & $6.86 \pm 0.43$ & $11.86 \pm 0.76^{\dagger}$ & $2.41 \pm 0.32^{+}$ & $7.67 \pm 1.43$ & $\mathrm{p} \leq 0.005$ \\
\hline cTnI (pg/ml) & $27.47 \pm 2.58$ & $30.58 \pm 2.84$ & $9.12 \pm 2.39^{+}$ & $28.26 \pm 1.21$ & $\mathrm{p} \leq 0.004$ \\
\hline $\mathrm{ADA}(\mathrm{U} / \mathrm{L})$ & $42.71 \pm 3.74$ & $28.38 \pm 3.57$ & $15.12 \pm 0.67^{\dagger}$ & $39.94 \pm 2.71$ & $\mathrm{p} \leq 0.007$ \\
\hline
\end{tabular}

Note: Data are expressed as mean \pm standard deviation. + as superscript in the row denotes significant difference in comparison with control group. $(p<0.01)$. For example, + superscript in the Hcy demonstrates significant difference between 40 and $80 \mathrm{mg} / \mathrm{kg} /$ day in comparison with control group.

Table 2 Comparison of oxidative stress markers following sertraline administration with different doses between treatment and control groups

\begin{tabular}{lccccc}
\hline Parameters & Control & $40 \mathrm{mg} / \mathrm{kg} /$ day & $80 \mathrm{mg} / \mathrm{kg} /$ day & $20 \mathrm{mg} / \mathrm{kg} /$ day & $\mathrm{p}$ value \\
& & & & \\
\hline MDA (nmol/ml) & $3.02 \pm 0.42$ & $3.73 \pm 0.39$ & $9.68 \pm 0.93^{+}$ & $4.18 \pm 0.55$ & $\mathrm{p} \leq 0.003$ \\
SOD(U/gHb) & $1486.77 \pm 82.66$ & $1479.53 \pm 44.31$ & $1028.19 \pm 72.59^{+}$ & $1519.66 \pm 126.71$ & $\mathrm{p} \leq 0.008$ \\
CAT(k/gHb) & $79.83 \pm 7.26$ & $77.81 \pm 9.55$ & $35.18 \pm 3.61^{+}$ & $83.67 \pm 11.31$ & $\mathrm{p} \leq 0.008$ \\
GSH-Px(U/mgHb) $99.26 \pm 4.19$ & $87.96 \pm 3.77$ & $41.48 \pm 2.29^{+}$ & $93.52 \pm 6.56$ & $\mathrm{p} \leq 0.007$ \\
PON(U/L) & $81.62 \pm 9.27$ & $74.57 \pm 6.48$ & $1.64 \pm 5.16^{+}$ & $79.80 \pm 7.86$ & $\mathrm{p} \leq 0.004$ \\
\end{tabular}

Note: Data are expressed as mean \pm standard deviation. $\dagger$ as superscript in the row denotes significant difference in comparison with control group. $(\mathrm{P}<0.01)$. For example, $\uparrow$ superscript in the MDA parameter demonstrates significant difference between $80 \mathrm{mg} / \mathrm{kg} /$ day group in comparison with control group.

neurons membrane phospholipids and changes their performance and ultimately may affect the serotonergic receptor function (6). In this study, sertraline at dose $80 \mathrm{mg} / \mathrm{kg}$ dose increases MDA compared with the control. A study was conducted by Sarandol et al. and any changes were not observed in oxidative stress parameters such as MDA during use of 6 week different antidepressants drugs (venlafaxine, reboxetine + sertraline, sertraline or reboxetine) (15). In contrast, Bilici et al. reported reduction of oxidative stress in patients with depressive disorder during treatment with SSRI (16). In addition, Kotan et al in 2005, demonstrated MDA reduction in major depressive disorder during long-term antidepressant therapy (17). Michalakeas et al. showed a decreased MDA level in depressed patients who received sertraline.
The overall results were not consistent with the results of present study (18). Since MDA production possesses a direct relationship with free radicals, thereby possibly in dose of $80 \mathrm{mg}$, the amount of free radicals increases and MDA is subsequently enhanced. Kumar et al. reported reversible conditions of low antioxidant levels as SOD and CAT via sertraline administration at doses 5 and 10 $\mathrm{mg} / \mathrm{kg}$. Several studies have been demonstrated neuroprotective and antioxidant effects of antidepressant drugs (32-34) and same author suggested antioxidant properties of sertraline on neurons. Studies on side-effects of ROS on neurons reveals its-induced neurons membranes viscosity changes and consequently impression of catecholaminergic and serotonergic receptor functions (35). Norepinephrine and dopamine as 
catecholamines are related with the oxidative stress, hence, elevated catecholamine metabolism may incremental effect of radical burden. Kumar described possible mechanism of action of sertraline ( 5 and $10 \mathrm{mg}$ ) in the lowering of oxidative stress and it was attributed to antioxidant effect of sertraline in increase of net serotonergic transmission of neurons. Battal et al. reported elevation of oxidative stress (MDA increase and decrement of antioxidant enzymes) in rats that administered $80 \mathrm{mg} / \mathrm{kg}$ of sertraline which is consistent with our study (19). Nevertheless, sertraline effect on oxidative stress probably is ascribed to drug dose, in the low dose as antioxidative effect and in the high dose as trigger of oxidative stress. Overall, mechanism of action of sertraline-induced oxidative stress in the high dose is controversial and debatable.

In this study, we encountered a significant reduction in all antioxidant enzymes. Superoxide dismutase (SOD) is known as first anti-radical enzyme that inhibit the high-production of free radicals. A noticeable decrease in the enzyme activity level, in present work, observed following administration of high doses of sertraline. Battal et al. observed a reduced activity of the enzyme at high dose of sertraline (19). Decreased SOD activity could be attributed to excessive accumulation of superoxide anion radical as one of the important free radicals are involved in lipid peroxidation (19). Reduced activity of catalase (CAT) which is considered as another important antioxidant enzyme involved in removing $\mathrm{H}_{2} \mathrm{O}_{2}$ was observed in the high doses of sertraline. Battal et al. also demonstrated a reduced activity of CAT subsequently administration of three different doses of sertraline (19). Bilici et al. reported reduction of antioxidant enzymes activity following administration of 3 months SSRI (16). A significant reduction of CAT can be associated with increased production of $\mathrm{H}_{2} \mathrm{O}_{2}$.

Paraoxonase (PON) is pointed out as another important antioxidant enzyme in the body that there are three genotypes of these enzymes. PON1 is produced in the liver and is transmitted along with HDL into blood. PON1 has antioxidant trait and prevents LDL oxidation. PON2 possesses also antioxidant activity and is expressed in all cells and protects the cell from oxidative damage (20). PON3 also structurally and functionally similar to the type of PON1 but its substrates are different with PON1. Significant reduction of PON was observed in the dose of $80 \mathrm{mg} / \mathrm{kg}$. Battal et al. reported a reduction of PON level in all groups (19) also its increase pointed out by Kotan et al. after 24 weeks of antidepressant medication (21). Since, PON participates in reduction of lipid peroxidation, thus, its reduced activity could be attributed to participation in MDA elimination.

In this study, ADA activity was significantly increased. Herken et al. reported increase of ADA activity in patients with depression during antidepressant treatment and concluded its high activity may be applied as a diagnostic biomarker in patients with depression (22). In contrast, Elgun and et al. showed a reduced level of ADA activity in depression (23). ADA activity was associated with increased $\mathrm{T}$ cell activity as well as an indicator of T cell activation. On the other word, the level of ADA activity associated with neutrophils-mediated free radicals' production. Hence, the possible cause of increased activity of ADA may be ascribed to high activity of cell-mediated immunity.

ADA catalyzes unilaterally conversion of adenosine to inosine. Adenosine is known as potent antiinflammatory component that modulates inflammatory reactions of immune cells. Adenosine hinders vascular endothelial cell damage caused by neutrophils and modulates neutrophils/endothelial cell interaction. It should be noted that the accumulation of adenosine and deoxy adenosine possess harmful effects on the cells, so its catabolism is very important for cells health. The other factor may play essential role in elevation of ADA activity is the catabolic effect of ADA on destruction of excessive adenosine. In addition, Blardi et al. showed that administration of citalopram in depressed patients is led to increased adenosine (24). The administration of sertraline may take part in abundant adenosine production in immune cells (especially T-cells) and to remove the harmful effects of adenosine, ADA expression is elevated for prevention of adenosine enhancement. Present study significantly indicates high levels of Hcy in the treatment group in comparison of control. Since a relevance between Hcy and folic acid has been clarified, the notable increase of Hcy determines defeat in the Hcy methylation to methionine due to folic acid deficiency, also, sertraline effect on methionine cycle is assumed on Hcy enhancement. Hcy involves in the pathophysiology of neurodegenerative disorders and neuronal lesions and may participate to induce neurons apoptosis. Kruman et al. revealed the effect of Hcy on hippocampal neurons and NAD depletion which boosts oxidative stress, neuronal apoptosis and mitochondrial dysfunction (25). Folic acid and vitamin B12 involve in differentiation, development and function of the CNS and participated in the Hcymethionine metabolism. In addition, folic acid possesses tremendous effect in reducing of depression. In present study, a considerable reduction in homocysteine was denoted in 80 $\mathrm{mg} / \mathrm{kg}$ group in comparison of other ones and the control group. The main reason of homocysteine 
reduction in $80 \mathrm{mg} / \mathrm{kg}$ dose can be attributed to vitamin B 12 and folate sufficiency and/or sertraline with unknown mechanisms involves in the conversion of Hcy to methionine.

Increased plasma levels of cTnI as the main biomarker for diagnosis of cardiomyocytes damage utilizes than lactate dehydrogenase (LDH) and creatine kinase (CK). In this study remarkable decrease of cTnI in high dose of sertraline (80 $\mathrm{mg} / \mathrm{kg}$ ) revealed in comparison of other groups. Meanwhile, significant changes in the groups that received 20 and $40 \mathrm{mg} / \mathrm{kg}$ was not observed than the control ones. Xinxing et al. reported positive impact of sertraline, as antidepressant drug, in inhibition of stress and depression-induced heart damage and observed that sertraline inhibits cardiomyocytes injury in rats with chronic unpredictable stress (CUMS). In addition, based on the test of "evaluation of myocardial apoptosis" anti-apoptotic role of sertraline also reported in cardiomyocytes (26). It is worth noting that the protective effect of sertraline on the myocardium has been denoted by several studies such as Serebruany et al. (27). The accurate mechanism of protective function of sertraline in cardiomyocytes has not been yet clearly known. But, several studies have described that sertraline has vasodilatory role, the antiplatelet effects and protective effects of vascular endothelial cells and with the help of these factors involves in the inhibition of myocardial damage $(28,29)$. Since, in this study we encountered a significant reduction in homocysteine and cTnI in rats in dose of $80 \mathrm{mg}$, hence, sertraline can play fundamental role in the heart protecting.

\section{Conclusion}

In this study, administration of sertraline in dose of $80 \mathrm{mg} / \mathrm{kg}$ firstly increased oxidative stress and secondly involves in reduction of cTnI and Hcy. Therefore, regulation of sertraline dose in patients with depression can be very important to their health. In addition, it is likely that the prescription of antioxidant components in patients with depression might impress an essential role in preventing potential damage of oxidative stress.

\section{Conflict of interest}

The authors declared no potential conflict of interest with respect to the authorship, and/or publication of this study.

\section{References}

1. Lobatao KR, Cardosoa CC, Binfarea WR, Budnia J, Wagnera CLR, Brocardoa PS, et al. $\alpha$ Tocopherol administration produces an antidepressant-like effect in predictive animal models of depression. Behav Brain Res 2010;209:249-59.

2. Tsuboi H, Tatsumi A, Yamamoto K, Kobayashi F, Shimoi K, Kinae N. Possible connections among job stress, depressive symptoms, lipid modulation and antioxidants. J Affect Disord 2006;91:63-70.

3. Peng Q, Masuda N, Jiang M, Li Q, Zhao M, Ross CA, et al. The antidepressant sertraline improves the phenotype, promotes neurogenesis and increases BDNF levels in the R6/2 Huntington's disease mouse model. Exp Neurol 2008;210:154-63.

4. Duan W, Peng Q, Masuda N, Ford E, Tryggestad E, Ladenheim B, Zhao $\mathrm{M}$ et al. Sertraline slows disease progression and increases neurogenesis in N171-82Q mouse model of Huntington's disease. Neurobiol Dis 2008;30:312-22.

5. Abdelmajeed NA. Oxidative Tissue Damage Induced by Citalopram in Rat Different Organs. Res J Med and Medical Sci 2009;4:580-6.

6. Atmaca M, Tezcan E, Kuloglu M, Ustundag B, Tunckol, H. Antioxidant enzyme and malondialdehyde values in social phobia before and after citalopram treatment. Eur Arch Psychiatry ClinNeurosci 2004;254:231-5.

7. Cumurcu BE, Ozyurt H, Etikan I, Demir S, Karlidag R. Total antioxidant capacity and total oxidant status in patients with major depression: Impact of antidepressant treatment. Psychiat Clin Neuros 2009;63:639-45.

8. Hoshino T, Yamada K, Masuok, K, Tsuboi I, Itoh K, Nonaka K. Elevated adenosine deaminase activity in the serum of patients with diabetes mellitus. Diabetes Res Clin Pract 1994;25:97-102.

9. Yao JK, Dougherty GG, Reddy RD, Matson WR, Daouk RK, Keshavan MS. Associations between purine metabolites and monoamine neurotransmitters in first-episode psychosis. Front Cell Neurosci 2013;7:90.

10. Nehler MR, Talor LM, Porter JM. Homocysteine as a Risk Factor for Atherosclerosis: a review. J Cardiovasc Sur 1997;5:559-67.

11. Fartashvand M, Nadalian MG, Sakha M, Safi S. Elevated Serum Cardiac Troponin I in Cattle with Theileriosis. J Vet Intern Med 2013;27:194-9.

12. O'Brien PJ, Landt Y, Ladenson JH. Differential reactivity of cardiac and skeletal muscle from various species in a cardiac troponin I immunoassay. Clin Chem 1997;43:2333-8.

13. Collinson PO, Gaze DC. Biomarkers of cardiovascular damage and dysfunction- an overview. Heart Lung Circul 2007;16:71-82.

14. Adams JE, Bodor GS, Dávila-Román VG, Delmez JA, Apple FS, Ladenson $\mathrm{JH}$, et al. Cardiac troponin I a marker with high specificity for cardiac injury. Circulation 1993; 88:101-6.

15. Sarandol A, Sarandol E, Eker SS, Erdinc S, Vatansever E, Kirli S. Major depressive disorder is accompanied with oxidative stress: Short-term antidepressant treatment doesnot alter oxidativeantioxidative systems. Hum Psychopharmacol 2007;22:67-73.

16. Bilici M, Efe H, Koroglu MA, Uydu HA, Bekaroglu M, Deger O. Antioxidative enzyme activities and lipid peroxidation in major depression: alterations by antidepressant treatments. J Affect Disord 2001;64:43-51.

17. Kotan VO, Sarandol E, Kirhan E, Ozkaya G, Kirli S. Effects of long-term antidepressant treatment on oxidative status in major depressive disorder: a 24-week follow-up study. Psychiat Clin Neuros 2005;59:616-20.

18. Michalakeas CA, Parissis JT, Douzenis A, Nikolaou M, Varounis C, Andreadou I, et al. Effects of Sertraline on Circulating Markers of Oxidative Stress in Depressed Patients with Chronic Heart Failure: A Pilot Study. J Cardiac Failure 2011;17:748-54.

19. Battal D, Yalin S, Eker ED, Aktas A, Sahin NO, Cebo M, et al. Possible role of selective serotonin reuptake inhibitor sertraline on oxidative stress responses. Eur Rev Med Pharmacol Sci 2014;18:477-84.

20. Reddy ST, Wadleigh DJ, Grijalva V, Ng C, Hama $\mathrm{S}$, Gangopadhyay A, et al. Human paraoxonase-3 is an HDLassociated enzyme with biological activity similar to paraoxonase-1 protein but is not regulated by oxidized lipids. Arterioscler Thromb Vasc Biol 2001;21:542-7.

21. Kotan VO, Sarandol E, Kirhan E, Ozkaya G, Kirli S. Effects of long-term antidepressant treatment on oxidative status in major depressive disorder: a 24-week follow-up study. Prog Neuro psycho pharmacol Biol Psychiatry 2011;35:1284-90.

22. Herken H, Gurel A, Selek S, Armutcu F, Ozen ME, Bulut M, et al Adenosine Deaminase, Nitric Oxide, Superoxide Dismutase, and 
Xanthine Oxidase in Patients with Major Depression: Impact of Antidepressant Treatment. Arch Med Res 2007;38:247-52.

23. Elgun S, Keskinege A, Kumbasar H. Dipeptidyl peptidase IV and adenosine deaminase activity. Decrease in depression. Psycho neuro endocrinol 1999;24:823-32.

24. Blardi P, de Lalla A, Urso R, Auteri A, Dell'Erba A, Bossini L, et al. Activity of Citalopram on Adenosine and Serotonin Circulating Levels in Depressed Patients. J Clin Psychop 2005;25:262-6.

25. Kruman II, Culmsee C, Chan SL, Kruman Y, Guo S, Penix L. Homocysteine elicits a DNA damage response in neurons that promotes apoptosis and hypersensitivity to excitotoxicity. J Neurosci 2000;20:6920-36.

26. Xinxing W, Wei L, Lei W, Rui Z, Baoying J, Lingjia Q. A Neuroendocrine Mechanism of Co-Morbidity of Depression-Like Behavior and Myocardial Injury in Rats. PLoS ONE 2014;9: e88427.

27. Serebruany VL, Glassman AH, Malinin AI, Nemeroff CB, Musselman DL. Platelet/endothelial biomarkers in depressed patients treated with the selective serotonin reuptake inhibitor sertraline after acute coronary events the Sertraline anti-depressant Heart Attack Randomized Trial (SADHART) Platelet Sub-study. Circulation 2003;108:939-44.
28. Palekar N, Eisman J. Serotonin syndrome with ziprasidone and sertraline. J Neuropsychiat Clin Neurosci 2013;25:E1.

29. Santra R, Chaudhuri PR, Dhali D, Mondal S. Suicidality and suicide attempt in a young female on long-term sertraline treatment. Indian J Psychol Med 2012;34:391-3.

30. Aebi H. Catalase in vitro. Methods Enzymol 1984;105:121-6.

31. Richter RJ, Furlong CE. Determination of paraoxonase (PON1) status requires more than genotyping. Pharmacogenetics 1999; 9:745-53.

32. Zafir A, Banu N. Antioxidant potential of fluoxetine in comparison to Curcuma longa in restraint-stressed rats. Eur J Pharmacol 2007; 572:23-31.

33. Eren I, Naziroğlu M, Demirdaş A. Protective effects of lamotrigine, aripiprazole and escitalopram on depression-induced oxidative stress in rat brain. Neurochem Res 2007;32:1188-95.

34. Eren I, Naziroğlu M, Demirdaş A. Venlafaxine modulates depression-induced oxidative stress in brain and medulla of rat. Neurochem Res 2007;32:497-505.

35. Takuma K, Baba A, Matsuda T. Astrocyte apoptosis: implications for neuroprotection. Prog Neurobiol 2004;72:111-27. 